\title{
REIRACTION
}

The article specified below is retracted. It is an inadequate review of recently published articles that appeared in Brazilian scientific publications, contains no original results, and was written for the information of readers of Clinics. The authors have been notified and agree with the retraction.

- Patel K, Caramelli B, Gomes A. A survey of recently published cardiovascular, hematological and pneumological original articles in the Brazilian scientific press. Clinics. 2011;66(12):2159-68. 


\title{
REVIEW
}

\section{A survey of recently published cardiovascular, hematological and pneumological original artic'ss in the Brazilian scientific press}

\author{
Kavita Kirankumar Patel, Bruno Caramelli, Ariane Gomes \\ Hospital das Clínicas, Faculdade de Medicina, Universidade de São Paulo/SP, Brazil.
}

\begin{abstract}
Recent original scientific contributions published in selected Brazilian eriodicals and classifiable under cardiovascular and pulmonary subject categories cover a wide range $c$ b specialties, both clinical and exprimental. Because they appear in journals with only recently enhanced vibility, ve have decided to highlight a number of specific items appeared in four Brazilian journals, because we understa. ' that this is an important subsidy to keep our readership adequately informed. These papers covr ex insive sub-areas in both fields.
\end{abstract}

KEYWORDS: Cardiovascular; Pneumology; Clinical science; Basic resec th.

Patel KK, Caramelli B, Gomes A. A survey of recently published cardiovascular, hematological a 'oneumological original articles in the Brazilian scientific press. Clinics. 2011;66(12):2159-2168.

Received for publication on September 27, 2011; First review completed on Novem, r 7, ? n, cepted for publication on November 7, 2011

E-mail: bcaramel@usp.br

Tel.: $55112661-5376$

\section{INTRODUCTION}

Recent original scientific contributions publish $d$ in selected Brazilian periodicals and classifiable unde Cardiovascular, Hematological and Pulmonar, sub; it categories cover a wide range of sub speci lies, oth clinical and experimental. Journals in which $t^{\prime}$ ey appear ' (Arquivos Brasileiros de Cardiologia, Jorn s sileiro de Pneumologia, Revista Brasileira de Cirurgia Cardio. scular, Revista da Associação Médica Brasileira) have only rec.ntly acquired an enhanced level of visibili . Hence we understand that is appropriate and nece sary to $\mathrm{t}$ hlight a number of specific items appeared in these fou Brazilian journals, because we understand that $t_{1}$ is a important subsidy to keep our readership riately intormed. These 113 papers (49 Cardiovascul a 3 atological, 64 Pneumological, 4 of which are in erdisciplinary) cover extensive sub-areas in bo ${ }^{+}$lds. S. action of papers to be highlighted was directe towa de giv g not only information about the resea $\mathrm{bu}^{+}$also show the range of distribution of this vrork. 1 st (but not all) of it stems from Brazilian based w k. Table, 1 and 2 specify how they are distributed betw the sub-specialties of the three major biomedical are of $\mathrm{k}_{1}$ wledge.

Table 1 di plays relati distribution frequencies of 52 selected pa ers paners on Cardiology. Thirty six papers are surgical, sixtee clinical. Within the surgical papers, Coronary to y byp is surgery reports, not surprisingly

Cr yright 20 - -INICS - This is an Open Access article distributed under the $\mathrm{ns}$ the Creative Commons Attribution Non-Commercial License (http:// creative nmons.org/licenses/by-nc/3.0/) which permits unrestricted noncommercia ${ }^{\circ}$ distribution, and reproduction in any medium, provided the original work is properly cited.

No potential conflict of interest was reported. were ur most frequent hits. Within this category 5 articles cove $\mathrm{d}$ the themes of scores and risks. Magedanz et al. ${ }^{1}$ n iructed a score risk model for use in daily practice to predict the risk of mediastinitis for patients undergoing oronary artery bypass grafting. The score includes routinely collected variables and is simple to use. Cadore et al. ${ }^{2}$ develop a score system capable to predict mortality in patients submitted to myocardial revascularization surgery, using clinical variables easy to obtain, which showed capability to predict mortality in patients submitted to myocardial revascularization surgery in our Hospital. Three papers focused on EuroSCORE: de Carvalho et al. ${ }^{3}$ critically analyzed the EuroSCORE logistic model application in 2,692 patients undergoing Coronary Artery Bypass Grafting in four public hospitals in the Rio de Janeiro and claim that the differences in the prevalence rates for the risk factors associated with its low power of discrimination, hamper recommendation for its use in Brazil, without essential adjustments. Sa et al. ${ }^{4}$ evaluated EuroSCORE applicability in patients undergoing coronary artery bypass graft surgery at the Division of Cardiovascular Surgery of Pernambuco Cardiologic Emergency Medical Services and found it to be a simple and objective index, revealing a satisfactory discriminator of postoperative evolution in patients undergoing CABG surgery at their institution. Nery et al. ${ }^{5}$ compared the Cleveland Clinical Score and EuroSCORE when evaluating patients submitted to elective coronary artery bypass grafting in Rio Grande do Sul and found both to be effective to evaluate risk of death in patients electively submitted to CABGS.

Two papers looked at the interaction of exercise with Coronary Artery bypass surgery: Botega et al. ${ }^{6}$ assessed the behavior of cardiovascular variables during an in-hospital cardiovascular rehabilitation program in patients after myocardial revascularization surgery and conclude that 
Table 1 - Distribution of highlighted Cardiology, Hematology articles by subject categories.

\begin{tabular}{lccc}
\hline General subjects & Sub-categories & \# of hits & reference \\
\hline surgical & Coronary Artery Bypass & 11 & $1-11$ \\
& $\begin{array}{l}\text { Surgery } \\
\text { Valve }\end{array}$ & 9 & $12-20$ \\
& Congenital Heart & 4 & $21-24$ \\
& pathology & & \\
& Transplant & 3 & $25-27$ \\
clinical & Other & 8 & $28-36$ \\
& Hypertension & 4 & $37-40$ \\
& Exercise & 2 & $40-41$ \\
Hematology & Congestive Heart Failure & 3 & $42-44$ \\
Renal & other & 8 & $45-52$ \\
& General & 3 & $53-55$ \\
& Cardiovascular related & 2 & 56,57 \\
\hline
\end{tabular}

the exercises proposed proved to be safe with the change in key physiologic variables throughout the experiment below recommended values for the hospitalization phase. Furthermore, the RPE scale appears to have a correlation with some hemodynamic variables and thus may be a useful tool for this group of patients. Martini and Barbisan ${ }^{7}$ investigated the effect of physical activity in leisure time on the prognosis of patients two years after coronary artery bypass grafting and found that such activity does not modify the late prognosis but that the bypass graft itself promotes physical activity and improves long-term functional capacity.

Pulmonary function interested two cardiac surgery research groups: Guizilini et al. ${ }^{8}$ evaluated early portoperative pulmonary function in patients submitted to ifpump coronary artery bypass grafting, comparin the conventional midsternotomy with the ministerno. $n$ v approach and found that ministernotomy led $\delta$ bett preservation and recovery of pulmonary funct ?. Barros et al. ${ }^{9}$ evaluated respiratory muscle traininc per rmed after the revascularization surgery and found that it $\mathrm{V}$ increase ventilatory capacity.

Saphenous harvesting was studied y Hijazi ${ }^{10}$, who compared the difference in wound omplicatio and infection rates between two saphenous vein har esting techniques, long incision versus multiple sho. crrupted incisions (tunneling) for coronary tor. King Abdullah University Hospital - ord $n$ and found that veins harvested using saphenous $I_{\Lambda}$ tunneling were associated with fewer wr alu comp ations than the traditional longitudinal $\mathrm{m}$ nod.

Gabriel et al. ${ }^{11}$ assess wh ner tre main pulmonary artery controlled perf ion ar cardiopulmonary bypass modifies brain natri etic peptic. levels expressed by the ventricular myocar $\mathrm{Au}$. and found that main pulmonary artery controlled perfusio. for 30 minutes did not yield substantial $\mathrm{mr}$ ifications in brain natriuretic peptide expression 0 in $t^{1} \mathrm{e}$ histological pattern of the right ventricular vocar ium.

Valve surgen, was $t^{1}$ object of nine papers, four on mitral $y$ surge nree on the aortic valve and two gener Lins al. ${ }^{12}$ studied aims to evaluate the surgical treat ent $c$ atr. fibrillation with ultrasound ablation concoms to mitral surgery in patients with permanent atrial fibri. tion and claim that patients who received treatment for atrial fibrillation simultaneously with valvar surgery had advantages related to the control group.
Table 2 - General distribution of highlighted themes in Pneumology broken down into subject specities.

\begin{tabular}{lcc}
\hline General themes & hits & referf \\
\hline asthma & 13 & $8,9,35$, \\
Mechanics and Ventilation & 11 & $79-88$ \\
Lung Infections & 10 & $89-c^{\circ}$ \\
COPD & 5 & $9 /, j 8$ \\
Oncology & 5 & -113 \\
Other & & \\
\hline
\end{tabular}

Benfatti et al. ${ }^{13}$ analyzed the ir uence of sing of epsilon aminocaproic acid in the 1 edir and red-cell transfusion requirement in the irst anty-tour hours postoperative of mitral valve sur ery. They nclude that the epsilon aminocaproic acid $\mathrm{w}$, le to reduce the bleeding volume and the red-cell tra sfusion equirement in the immediate postoperative of p-tients submi ed to mitral valve surgery. Guedes et al. ${ }^{14}$ esct be a technique and results of mitral valve treatme t by aortic cannula $n f$ cardiac pulmonary bypass and claim it is a simple, sa. and reproducible technique. Guedes et al. ${ }^{15}$ analyze cardiac morphology and function using rea time mensional echocardiography in individuals subn $+d$ to mitral valve repair with Double Teflon technique. T, $y$ describe a left atrial and ventricle reverse remodeling as ciated with an improvement in left atrial n... on during the study. Gaia et al. ${ }^{16}$ developed a cathete mounted aortic bioprosthesis for aortic implant and con lude that transapical implantation of catheterounte bioprosthesis is a feasible procedure. do Amaral et 1 stress the need for replacement of the valve, ascending aorta and aortic with coronary reimplantation in atients where anti-coagulation is undesirable, is increas$i$ g. They evaluated the hemodynamic performance of an aortic valved conduit made with glutaraldehyde treated bovine pericardium (AVCP) in animals and find that hemodynamic outcomes found are similar to physiological parameters. Dias et al. ${ }^{18}$ analyzed early and late results of aortic root reconstruction with aortic valve sparing operations and the composite mechanical valve conduit replacement. And claim that this has a low early and late mortality, a high survival free of complications and low need for reoperation. Lavitola et al. ${ }^{19}$ compared the effectiveness of Aspirin vs. Warfarin in thromboembolism prevention in patients with Atrial fibrilation and claim that in patients presenting fibrillation for less than a year and no previous embolism, aspirin is little effective. However, in patients with lower-risk mitral valvulopathy (mitral regurgitation and mitral biological prosthesis), especially in cases presenting contraindication to or low adherence to warfarin, aspirin use can present some benefit in thromboembolism prevention. de Campos et al. ${ }^{20}$ To evaluate the occurrence of complications in patients with mechanical heart valve prostheses undergoing anticoagulant therapy optimized through specialized clinics. And find that the period of time in which patients remain within the desired anticoagulation interval directly relates with occurrence of complications.

Congenital heart pathology was studied in four selected papers. Maluf et al. ${ }^{21}$ studied patients with complex congenital heart disease, characterized by right ventricle hypoplasia, had a palliative surgical option with one and a half ventricular repair and claim that surgical treatment 
of the congenital cardiac anomalies in the presence of a hypoplastic right ventricle by means of one and a half ventricle repair has the advantages of reducing the surgical risk of biventricular repair compared to the Fontan circulation. da Rocha et al. ${ }^{22}$ assessed the morbidity and mortality after Jatene's operation using lactate as the main marker and claim that morbidity and mortality can be assessed with the serum lactate levels, suggesting increased values in the third hour is suggestive of a worse prognosis. de Souza et al. ${ }^{23}$ studied the mortality rate of children undergoing to Fontan operation and determined whether the hypoplastic left heart syndrome is not a risk factor for hospital mortality. Rosa et al. $^{24}$ checked on the frequency and types of congenital heart defects in a sample of patients with oculo-auriculovertebral spectrum, in an effort to correlate presence of these defects with other clinical characteristics and evolution. They find that cardiac malformations, mainly conotruncal and septal defects, are frequent among such patients. Frequency found in our study was statistically similar to the majority of works described in literature where it ranged from 18 to $58 \%$.

Cardiac Transplants. Coronel et al. $^{25}$ described and compared pre-and postoperative physical and pulmonary capacity of patients who underwent heart transplantation and conclude that changes in ventilatory function of subjects undergoing cardiac transplantation are predictable: respiratory muscle strength and lung capacity recover within two weeks and a good strategy is to aim at at an improvement of functional capacity above pre-operative levels. Yoshimo' et al. ${ }^{26}$ studied cardiovascular behavior and safety rega. ing a low-intensity exercise program for heart transwlant candidates with severe heart failure and find that it $r$ oved to be safe and well tolerated, but requires mo itorin Dinkhuysen et al. $^{27}$ evaluated pulmonary artery "ess re with sodium nitroprusside before transplantin and im that the procedure may allow conversion, orthotop. technique.

Nine papers on cardiac surgery fall under rious

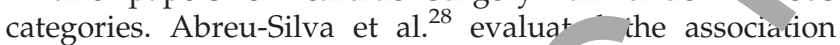
between plaque volume before th stentin through angiography and clinical outcomes a d conclud that the volume of atheromatous plaques befor stenting , as higher in patients with MACE on clinical follow one year, regardless of other predictors or al. ${ }^{29}$ endeavored to associate clinical aria ses vith Quality of Life scores in patients with stable ronary artery disease before percutaneous corc un interv ation and with unfavorable outcomes, 12 onths ar tre procedure. In the presence of coronary tery aseasc, patients with comorbidities present a $h$ her ree of Quality of Life impairment. Duarte et $\because 0$ detern ad the reliability of central atrial venous bl $s a$ asometry data as estimates of cardiac index in patien $\mathrm{s}$ who $u$. Jerwent cardiac surgery and found that $\mathrm{SvO}_{2}$ a d the $\left.\mathrm{C}(\mathrm{a}-\mathrm{v})_{2}\right)_{2}$ correlated with low cardiac output. Sil et al ${ }^{31}$ proposed and developed a risk index to predict $A$ ial fi illation after cardiac surgery.

Because 0. ncern bout adverse hemodynamic effects of closu the $r i$ ardium most heart surgeons prefer to ave $d$ the modure even though it may reduce the risk of cr liac jury aring chest re opening, especially to the righ. Itricle, aorta and coronary bypass grafts. Within this context, antas et al. ${ }^{32}$ propose a simple method to facilitate resternotony during subsequent re-operative procedures. Riedi et al. ${ }^{33}$ determined the strength of respiratory muscle in cardiac surgery and its relationship with the postoperative pulmonary complications but $f$ and that preoperative respiratory strength couldn't $r$ a predictor of postoperative pulmonary complication. eal $\mathrm{e}^{t} \mathrm{al}^{34}$ report on a method of removing intravascula fr eign 1 odies, catheters with the use of various endovascu " te iniques and procedures. Conclusion Percutaneous rueval of intravascular foreign bodies is $\mathrm{co}$-idered $\mathrm{gc}^{\mathrm{A}} \mathrm{d}$ standard treatment because it is a minimally ' nvas' e, relatively simple, safe procedure, $y$ an low $\mathrm{CO}_{1}$ slication rates compared to conventional s rgical trec ment. Laizo et al. ${ }^{35}$ analyzed the complications at increas the permanence of the patients submitted carc sur ry at intensive care unit and conclude that $\mathrm{v}$ are related to respiratory function, chronic ob ructive $P$ 'monary disease, tabagism, pulmonary conge time of permanence under $\mathrm{MV}$, diabetes, infectic $s$, re.. insufficiency, stroke and hemodynamic instability. Sa et ${ }^{36}$ studied clinical features, complication ana n-hospital outcomes of patients operated for postinf ction cular septal rupture and claim that the need fo. ras ctive arugs, hemodynamic instability and cardiogenic St $k$ were associated with higher rates of

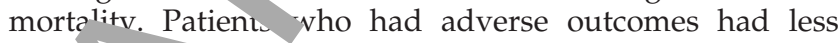
ventri lar tion and higher score in the EuroSCORE.

Of th $t$ enty papers selected on Clinical Cardiology, hypertens in was the most frequent hit. Ferreira et al. ${ }^{37}$ investigatec the prevalence of cardiovascular risk factors ong the elderly treated by SUS in the city of Goiania, stat of Goias, Brazil and found that factors occur simul ineously in more than half of the elderly individuals, and ie most prevalent ones were: arterial hypertension, - al obesity and sedentary lifestyle. Arruda et al. ${ }^{38}$ estimated the prevalence of hypertension and describe the haracteristics of patients with hypertension infected by HIV/AIDS. They conclude that a high frequency of uncontrolled hypertensive patients and cardiovascular risks in HIV-infected patients point out to the need for preventive and therapeutic measures against hypertension in this group. Queiroz et al. ${ }^{39}$ evaluate the prevalence of high blood pressure in schoolchildren from public schools and its association with anthropometric indicators. They identified an association between excess weight with high blood pressure levels, which emphasizes the need for intervention and for nutritional status control measures, such as dietary education programs aimed at the prevention and treatment of obesity as a risk factor for cardiovascular diseases in the pediatric and older age ranges. Monteiro et al. ${ }^{40}$ analyzed the effect of a 13-week aerobic training program on blood pressure, body mass index and glycemic levels in elderly women with type-2 diabetes mellitus and found that the program was enough to promote significant decrease in the diastolic blood pressure and glycemic levels.

Exercise in itself was examined by Camara et al. ${ }^{41}$ who compared the cardiovascular responses recorded during the assessment of muscle strength and endurance for two exercises commonly used in patients with intermittent claudication and conclude that isokinetic strength and endurance testing in such patients results in elevation of heart rate, systolic blood pressure and double product values during the exercises. These increases are higher during the muscle endurance exercises and in those involving greater muscle mass, suggesting that strength testing of small muscle groups causes less cardiovascular overload in these patients. 
Heart Failure is highlighted in three articles. Ribeiro et $\mathrm{al}^{42}$ evaluated the cost-effectiveness of Implantable Cardioverter Defibrillators in congestive heart failure patients under two perspectives in Brazil: public and supplementary health systems. They conclude that the incremental cost-effectiveness ratio of Implantable Cardioverter Defibrillators is elevated in the general heart failure population, in either the public or private perspective. A more favorable result occurs in patients with a high sudden death risk. De Aguiar et al. ${ }^{43}$ To evaluate the predictors of morbidity and mortality in acute coronary syndrome in the long term. And conclude that heart failure upon admission, creatinine, age and HR were independent predictors of mortality. They also claim that heart failure patients treated before 2002 had a worse survival when compared with that seen after 2002 and the that change in therapy was responsible for the improvement. Aguiar et al. ${ }^{44}$ evaluated the role of severe depression in the outcome of patients with decompensated heart failure. And conclude that patients with severe depression showed a higher degree of neurohormonal stimulation despite their lower degree of ventricular dysfunction. The pathophysiological changes related to depression, leading to increased neurohormonal stimulation and cytokines, probably contributed to this more intense clinical manifestation even in the presence of less cardiac damage.

Under a general category of sundry themes, Alves et al. ${ }^{45}$ evaluated whether the chronic and regular use of statins, for a period of six months, prevents atrial fibrillation after elective cardiac surgery and claim the the strategy reduced the incidence of atrial fibrillation after elective cardiac surgery. Da Silva et al. ${ }^{46}$ evaluated the effects of nandrol ne decanoate on the electrocardiographic profile, gly gen content and total-protein profile of skeletal and co diar muscles, as well as the plasma albumin concentr cions rats, concluding that major cardiac changes are $t$ sgered at an early stage, which indicates a hierarchy in 'e sence of changes that compromise the homeostasis of the $\mathrm{D}^{1} \mathrm{~V}$. Diogo et al. ${ }^{47}$ evaluated the possible ass on betweer NSAIDs and Contrast-Induced Nephrc athies and conclude that there was no association. Fagı ides and $c$ stro ${ }^{48}$ endeavored to determine the predictive value of esting heart rate before exercise stress testing for .1 . vascular and all-cause mortality, concluding in an independent predictor of cardiovascular ana all aus mortality. Feliciano-Alfonso et al. ${ }^{49}$ estimated pre ence and distribution of cardiovascular risk $f_{r} \ldots$ and $\mathrm{N}$ tabolic Syndrome in young individuals admi ed to Vational University of Colombia in Bogota ar enc anteru a prevalence of modifiable cardiovasc 1 ar $\mathrm{r}_{4}$ factors which justifies promotion of therapeu+ lifestyle hanges among this age group in Colombia ${ }^{1}$ et al. ${ }^{50}$ tested the safety, feasibility and early myocardial an ingenic effects of transthoracic intramyocardia ${ }^{1}$ phVEGF165 dministration for refractory angina in no $r$ tion atients. They claim that the procedure resulted fear le ar safe. Farly clinical and scintillographic data are prese. whic showed improvements in symptoms an $r^{\prime}$ ocara. $1 r$ rfusion, with regression of ischemia severit in tr atod areas.

$\mathrm{M}$ cardi con ictility alterations of isolated hearts of rats, su itted to ischemia and reperfusion with and without ac inistration of the omeprazole was evaluated by Gomes et a1. ${ }^{51}$ who concluded that omeprazole administration before ischemia induction significantly protected the myocardium function recovery. Minicucci et al. ${ }^{52}$ analyzed the presence of different patterns of remodeling in a murine model and its functional implicati as and found that animals that underwent coronary of usion showed two different patterns of remodeling, ne ar of $w^{1}$ ch constitute a predictor of ventricular dysfunction

Three Hematology studies are highlighted. Azamb ja and Garrafa $^{53}$ studied the extent of knowle, and acce tance of hemocomponents and hemoderivatives, sh ad stored, by Jehovah's Witnesses and pr posed bioet. al tools for any ethical and moral conflict identifiea $n$ their relationship with physicians and de tists. The conclude that Jehovah's Witnesses are s on by their " noral outsiders" (i.e., physicians and dertists, sthe religious group that simply "does not usf blood". "though, several blood treatments are now a permitted it does not deprive them from a free onvicu to refuse blood treatments. Ammirati et al. ${ }^{54}$ 11ced epoetin correct anemia and found a decrease in $\mathrm{m}, \mathrm{bia} \mathrm{y}$ and increases survival and quality of life in end- age rf an isease. Macedo et al. ${ }^{55}$ evaluated the adequacy $\&$ ar coaguration therapy in patients with atrial fibrillation 1 owed in a private clinic specialized in cardiolo in accorda with the American and European societies of congy guidelines/2006 and with the Brazilian c ir clines/2003. They conclude that anticoagulant therapy 's been adequately prescribed for the majority of patients, at ough still far from ideal, especially in a $\rightarrow \log$ clinic.

Two apers are highlighted in the field of interaction of renal an cardiovascular pathophysiology. Correia et al. ${ }^{56}$ raluate whether moderate renal dysfunction is associated wis. inT elevation in patients with acute coronary syndrome and found that moderate renal dysfunction is no associated with cTnT elevation in these patients. $c$ arvalho et al. ${ }^{57}$ evaluated the frequency and type of cardiovascular and renal/collecting system abnormalities seen in a sample of patients with Turner Syndrome and found that the frequency of such abnormalities was similar to that of previous studies, but most were found in routine exams after Turner Syndrome diagnosis.

In the field of Pneumology, we highlight 59 articles, the most frequent theme being asthma, with 13 hits. Roxo et al. $^{58}$ developed and validated a Portuguese-language version of the Asthma Control Test (ACT) for use in Brazil. Santos et al. ${ }^{59}$ evaluated treatment compliance and use of inhaled medications of patients with asthma receiving complementary pharmaceutical care. and found that counseling provided by the pharmacist to the patient was important to assist in the implementation of the appropriate inhalation technique. Sarinho et al. ${ }^{60}$ compared BCG vaccination involving a single intradermal dose and that involving multiple doses, and claim that the prevalence of asthma among individuals having received multiple doses of the BCG vaccine was no different than that observed among those having received a single dose. Sarria et al. ${ }^{61}$ assessed the psychometric properties of the official Brazilian Portuguese-language version of the Paediatric Asthma Quality of Life Questionnaire (PAQLQ) in a representative group of Brazilian children and adolescents with asthma. and conclude that the Brazilian Portuguese-language version of the PAQLQ showed good psychometric performance, confirming its cultural adequacy for use in Brazil. Razi and Moosavi ${ }^{62}$ determined whether serum total $\operatorname{IgE}$ levels and total eosinophil counts have any relationship 
with the response to routine pharmacological treatment in patients with acute asthma and conclude that serum total IgE levels, peripheral white blood cell counts and eosinophil counts cannot predict the response to the pharmacological treatment of patients with acute asthma. Reck et al. ${ }^{63}$ determined the proportion of asthma patients with a poor perception of dyspnea, correlating the level of that perception with the severity of acute bronchoconstriction, bronchial hyper-responsiveness, use of maintenance medication, and asthma control. Their results suggest that a significant proportion of asthma patients have a poor perception of dyspnea. Melo et al. ${ }^{64}$ evaluated whether the exhaled breath temperature, measured by a noninvasive method, is an effective means of monitoring patients with uncontrolled asthma and conclude that uncontrolled asthma, especially during exacerbations, is followed by an increase in exhaled breath temperature, which decreases after appropriate asthma control. Lima et al. ${ }^{65}$ endeavored to determine whether children and adolescents are able to perceive acute exercise-induced bronchoconstriction (EIB), as well as to measure the discriminatory power of a word labeled visual analog dyspnea scale in relation to the intensity of the FM. They note that among children and adolescents with asthma, the accuracy of this dyspnea scale improves as the post-exercise percentage fall in FEV(1) increases. However, the predictive value of the scale is suboptimal when the percentage fall in $\mathrm{FEV}(1)$ is lower. Dela Bianca et al. ${ }^{66}$ determined the prevalence and severity of wheezing in infants, using the standardized protocol devised for th "Estudio Internacional de Sibilancias en Lactantes" (EI International Study of Wheezing in Infants), as well as to determine the relationship between such wheezin, and physician-diagnosed asthma, in the first year of 1 i $c$. The conclude that the prevalence of wheezing episodt $\mathrm{am} \mathrm{ig}$ infants in their first year of life was high and $r d \mathrm{~d}$ an rly onset. The proportion of infants diagnosed $w^{\mathrm{i}}$ and treate for asthma was low. de Castro et al. ${ }^{67}$ ete ined the prevalence of symptoms of asthma, rhinitis ana topic eczema among students between 6 and 7, rs of age in the city of Londrina, Brazil. and found $t^{t}$ at the pr valence of symptoms of asthma, rhinitis and opic eczer a in our sample was within the range found the fac ities that participated in phases 1 and 111 of the IS Brazil. The low prevalence of physician- a nod asthma suggests that asthma continues to be $u$ der ay osed. Brandao et al. ${ }^{68}$ examined the clinical racteristics and the predictors of hospital a in a e to asthma among children and adolescen' with 'Mma ander treatment at a referral center. and $f$. nd $t^{\prime}$ at the principal predictor of hospital admission vas o ater asthma severity, calls for special attention $r$ ang giver the care of these patients. Borges et al. ${ }^{69} \mathrm{~d} f$ e $\mathrm{e}_{1}$ and validated an asthma knowledge questionnaire 1or use adult asthma patients in Brazil. Almeida et $a^{70}$ endeavore to describe socio-economic and behavioral spect of pregnant women with asthma and to analyzed ne eff cts of naternal asthma on certain perinatal parameters birth short. They found that socioeconomic level ars to a risk factor for asthma.

$P$ amon $m$ mechanics and ventilation contribute 11 papers to his $\mathrm{r}$ rew. 's reported above, Guizilini et al. ${ }^{8}$ evaluated $y$ postoperative pulmonary function in patients submitt to off-pump coronary artery bypass grafting, comparing the conventional midsternotomy with the ministernotomy approach. They conclude that ministernotomy leads to better preservation and recovery of pulmonary function. Barros et al. ${ }^{9}$ evaluated respiratory auscle training, performed after the revascularization surge $y$ and found that it may increase ventilatory capacity. Rir i et $? 3$ checked respiratory muscle strength in cardiac ir ery ar $d$ the relationship with the postoperative pulmonary $\mathrm{mr}$ ications and conclude that preoperative respiratory stren $y, n$ is not a predictor of postoperative pulmona complicat on. Fonseca et al. ${ }^{71}$ compared two respiratorv mus trair ng programs for improving the functional atonomy or stitutionalized elderly and found that 1 e traine groups improved functional autonomy. Silva $t$ al. ${ }^{72}$ asses ed the relationship between clinical and rope tive $r$ monary functional evaluation and occurren of pustoperative pulmonary complications. They claim tha the most important factors associated with aperative pulmonary complications were surgical sitc time 0 nesthesia, and ASA classification. Costa et al. ${ }^{73}$ compared $m, n$ inspiratory and expiratory pressures in 'alt 1 subjects with those predicted using the equations ropos previous studies and claim that previously no oed equations were unable to predict the pressures for 1 of the subjects in their sample. They concl that the sults of their study can facilitate the predic on o miratory muscle strength in healthy adult subjects in Brazil. D'Aquino et al. ${ }^{74}$ used clinical and spirometr findings in order to distinguish between the restrictive a $d$ nonspecific patterns of pulmonary function + results in patients with low FVC and a normal or elevated FE 1)/FVC ratio. They found that In many patients with reduc d FEV(1), reduced FVC, and a normal FEV(1)/FVC ratio he restrictive pattern can be identified with confidence - agh the use of an algorithm that takes the clinical diagnosis and certain spirometty measurements into account. Logrado et al. ${ }^{75}$ endeavored to determine the impact of positive reinforcement during spirometry on the measurement of VC in healthy volunteers They claim their results indicate the Importance of using the behavioral strategy in combination with traditional practice in order to obtain better results. The use of positive reinforcement during the determination of VC is described as an effective, simple and easily applied strategy. Rodrigues et al. ${ }^{76}$ evaluated the contribution of a new coefficient, the $\mathrm{FEF}(50 \%) / 0.5 \mathrm{FVC}$ ratio, obtained from the maximal expiratory flow-volume curve, to the diagnosis of obstructive lung disease and to test this coefficient in differentiating among patients considered normal, those with obstructive lung disease and those with restrictive lung disease They conclude that the $\mathrm{FEF}(50 \%) /$ $0.5 \mathrm{FVC}$ ratio is a potentially useful parameter in the differential diagnosis of OLD and correlates positively with the FEV(1)/FVC ratio. Silveira et al. ${ }^{77}$ endeavored to determine whether inspiratory muscle training can increase strength and endurance of these muscles in quadriplegic patients and found that quadriplegic patients can benefit from training at low loads (30\% of MIP), which can improve inspiratory muscle strength, FVC and expiratory muscle performance. Felix et al. ${ }^{78}$ compared the influence of two different ventilation strategies-volume-controlled ventilation (VCV) and pressure-controlled ventilation (PCV)-on the functional performance of lung grafts in a canine model of unilateral left lung transplantation using donor lungs harvested after three hours of normothermic cardiocirculatory arrest under mechanical ventilation. Their data indicate that in this model of lung transplantation showed that the functional performance of lung grafts was not influenced by 
the ventilation strategy employed during the first six hours after reperfusion.

Pulmonary and mediastinal infection contributes nine papers to this study, five of which on tuberculosis. Goncalves et al. ${ }^{79}$ described the epidemiological monitoring of exposure to tuberculosis in a hospital environment and to analyze the profile of the disease in a general teaching hospital and suggest that the proposed indicators can potentially help standardize epidemiological monitoring procedures for nosocomial tuberculosis. Gupta et al. ${ }^{80}$ In developing countries, sputum smear microscopy is the main tool for pulmonary tuberculosis case finding. The objective of the present study was to evaluate the diagnostic efficacy of Gabbett's staining (GS) and modified cold staining (MCS), both of which are two-step methods, in comparison with that of fluorescent staining (FS), which is a three-step method, for the detection of AFB in sputum smears. Conclusions: Although MCS and GS were found to be less sensitive than was FS, which is evaluated under fluorescence microscopy, the first two are promising methods for the diagnosis of tuberculosis. Lundgren et al. $^{81}$ determined the main causes of hemoptysis and endeavored to classify this symptom, in terms of the amount of blood expectorated, in patients hospitalized at a referral hospital for pulmonology. They suggest that all patients who present with hemoptysis should be investigated for tuberculosis and other possible infectious agents. Maciel et al. ${ }^{82}$ determined the principal adverse effects of the tuberculosis treatment regimen recommended by the Brazilian Ministry of Health and find that the overall incidence of adverse effects related to the new treatment regimen recommended by the Brazilian Ministry of $\mathrm{He}$ ch was high, even though none of those effects deman $2 \mathrm{~d}$ a change in the regimen, which was effective in the pa nt evaluated. Marques et al. ${ }^{83}$ determined the drug $r$ sistar profile of Mycobacterium tuberculosis in the st? of Mato Grosso do Sul, Brazil, between 2000 and $200 \mathrm{f}$ an. found high levels of resistance which undermine the efforts 'or tuberculosis control in Mato Grosso do Sul 'rozo et al. evaluated the efficacy of the scoring syst $n$, recom nended by the Brazilian National Ministry of $I$ ealth (NM I), for the diagnosis of pulmonary tuberculosis (TB) in $c$ ildren and adolescents, regardless of their HI s. They conclude that the NMH system significantly higher in the TB and TB/HIV group tha $1 \mathrm{n}$. we other two groups. Therefore, this scoring syste was valid for the diagnosis of pulmonary TB $\mathrm{i}$. popu tion, regardless of HIV status. Away from + bercu thee other papers deal with pulmonary anc nedir tinal mfections. Martinelli et al. ${ }^{85}$ determined the preva ice of nosocomial pneumonia in autopsies at a public iversity hospital in an attempt to identify an risk factors for nosocomial pneumonia and the pocential $p$. onostic factors associated with fatal nosocomi 1 pneumonia and with fatal aspiration pneumonia a $d$ to letermine whether patho-anatomical findings co late ith $\mathrm{n}$ socomial pneumonia or aspiration pneumor. The found a high prevalence of nosocor neurn. $i$, which was responsible for almost $25 \%$ of all of bn deatris. Smoking-related structural lesions and ilater pr monia all favored mortality. These finding croborate the results of various clinical studies on nosoco ial pneumonia. Mattiello et al. ${ }^{86}$ describe pulmonary function in children and adolescents with post-infectious bronchiolitis obliterans and evaluate potential risk factors for severe impairment of pulmonary function. They claim that such patients had a common pattern of severe pulmonary function imp rment, characterized by marked airway obstruction $\mathrm{d}$ prr lounced increases in RV and sRaw. The combination f sirom ric and plethysmographic measurements is describ. 'as nore useful for assessing functional damage, as well as in the follow-up of these patients, than either of these techniques used in isolation. Known sk ctors for respiratory diseases do not se $\mathrm{m}$ to be as ciated with severely impaired pulmonary function 1 PIBO. Senturk et al. ${ }^{87}$ determined the incide ce of loc and systemic infection in a sample of pa 'nts 'heter ed with thoracic catheters (TCs) and ide tifie the prognostic factors for catheter-related infecti 1. They cla that risk factors, such as advanced age, pro on catheterization, comorbidities, and inoperable mangnancy, increase the risk of catheterrelated infection Melo et al. report a case series of patients with $\mathrm{d}$ scen ing necrotizing mediastinitis (DNM) who were teated wI minimally invasive thoracic surgery. Conc ir is: We conclude that video-assisted thoracoscopy is a effective technique for mediastinal drainag the treawnent of DNM, with the benefits common mir in. pain, lowe coduction of inflammatory factors, earlier return to ac ities of daily living, and better aesthetic results.

Ch nic Obstructive Pulmonary Disease is the subject of four art les. Fernandes et al. ${ }^{89}$ evaluated the short-term impact $c$ tiotropium in patients with severe or very severe C. DD who complain of dyspnea despite being currently treaten with other bronchodilators and claim that the int duction of tiotropium into the treatment of such $p$ ients using long-acting beta(2) agonists improves pulnonary function and provides symptomatic relief, as perceived by patients in the short term. They claim that these results, obtained under real life treatment conditions, support the use of the salmeterol+tiotropium combination in specific treatment protocols for these patients. Ferrari et al. ${ }^{90}$ evaluated the health status (HS) of COPD patients and identified the main predictors of HS in these patients according to gender and claim that their results show an association between gender and HS in COPD patients. Age and dyspnea are determinants of HS in both genders. Araujo and Holanda ${ }^{91}$ determined whether Body mass index, airway Obstruction, Dyspnea, and Exercise capacity (BODE) index correlates with health-related quality of life in patients with COPD. and found that the BODE index score correlated with the scores of all of the mSGRQ domains in COPD patients with FEV(1) $<50 \%$. Therefore, COPD patients with $\mathrm{FEV}(1)<50 \%$ die sooner and have a poorer quality of life. Camargo and Pereira ${ }^{92}$ determined the correlations among various dyspnea scales, spirometric data, exercise tolerance data, and the Body mass index, airway Obstruction, Dyspnea, and Exercise capacity (BODE) index in patients with COPD. They suggest that multidimensional dyspnea scales should be applied in the evaluation of COPD patients. Chatkin et al. ${ }^{93}$ measured exhaled carbon monoxide (COex) levels in smokers with and without COPD. which did not differ significantly between smokers with COPD and those without, suggesting that there seems to be no major contraindications to their use in smokers with COPD. 
Lung Cancer is the subject of five articles. Machado et al. ${ }^{94}$ evaluated the effect of chemotherapy on the physical condition of patients with advanced lung cancer and observed a beneficial effect on the performance status of the patients. No significant changes in BMI or 6MWD were found during the study period, which might suggest the maintenance of the physical condition of the patients. Franceschini et al. ${ }^{95}$ assessed the quality of life of ling cancer patients, through the Treatment of Cancer Core Quality of Life Questionnaire (EORTC QLQ-C30) in conjunction with its supplemental 13-item lung cancerspecific module (QLQ-LC13). The objective of this study was to assess the reproducibility of the Brazilian Portuguese version of these questionnaires and findings show that these instruments were reproducible in this sample of patients with lung cancer in Brazil. Rodrigues et al. ${ }^{96}$ analyzed the association between paracoccidioidomycosis (Pcm) and cancer in a series of 25 cases and to review the literature on this topic and claim that a diagnosis of Pcm appears to increase the risk of lung cancer. Marchi et al. ${ }^{97}$ evaluated how pleurodesis is performed in South and Central America and found considerable variation among the countries evaluated in terms of the indications for pleurodesis, techniques used, and outcomes. Talc slurry is the agent most commonly used, and thoracoscopy is the technique of choice in Brazil. Brandao et al. ${ }^{98}$ analyzed the clinical and pathological aspects of bronchiolo-alveolar carcinoma and the survival in a sample of patients at clinical stage I. Their data indicate these aspects were similar to those of patien+ with bronchiolo-alveolar carcinoma evaluated in previc studies.

A number of studies fell into sundry categories. et al. ${ }^{99}$ evaluated predictors of health-related quali of $1 \mathrm{j}$ ? (HRQoL) in patients with interstitial lung dist $\mathrm{ad}$ found that these in patients the degree of dy nea 1 major impact on the physical and mental tRQoL, an depression had an impact on mental $\mathrm{H}^{\mathrm{T}} \mathrm{QO}_{\mathrm{L}}$. Antunes et al. ${ }^{100}$ determine the interobserver and intrao arver agreement in the diagnosis of inters ${ }^{+\cdots}$ lung diseases based on HRCT scans and the impact observe expertise, clinical data and confidence level on ich agreen nt. They conclude that interobserver and intrao erver ag ement in the diagnosis of ILDs based on HRCT so inged from fair to almost perfect and wa manced by radiologist expertise, clinical history and c nfid nce level. Navarro et al. ${ }^{101}$ evaluated the biological an unctional behavior of decellularized pulmonar nogra (Decell-H), treated by a sodium dodecil su ate so $-1 \%$ n $(0.1 \%$ ) and found that in their experimental ode' the Ducell-H behaved as an excellent valve sub itute ego-Fernandes et al. ${ }^{102}$ report on the function evaluatio experience with ex vivo perfusion of tw $v$ tonor lungs deemed unacceptable in Sao Paulo, Brazil. They 'aim that ex vivo evaluation model can improv oxygenation capacity of "marginal" lungs rejected fo tran plantation. It has a great potential to increase 'ng $c$, nor a rabilability and, possibly, to reduce the waiting e on $t^{\prime}$ list. Athanazio et al. ${ }^{103}$ profiled the chare stics ar alt patients with bronchiectasis, drawing omp, risons between cystic fibrosis patients and those $\mathrm{w} h$ bro chies is from other causes in order to determine whe. it is rational to extrapolate the bronchiectasis treatme from other causes. They conclude that causes and clinical manifestations of bronchiectasis are heterogeneous, and it is important to identify the differences. It is crucial that these differences be recognized so that ne strategies for the management of patients with bron iectasis can be developed. de Souza et al. ${ }^{104}$ determine the $r$ evalence of respiratory symptoms and smoking, as $h$ '1 s pulr onary function parameters among charcoal product 1 w rkers in three cities in southern Brazil. They indicate that respiratory symptoms and airflow reduct in the smoking workers. $D-1^{-1}$ e $-1 .{ }^{10}$ determined whether respiratory sympto is and chron bronchitis are associated with the use of jiomass $t_{t}$ ls among women residing in rural areas of th Ekiti Sta e, in southwestern Nigeria and claim that $t_{1}$ ires..... uerscore the need for women using biomar fuels their households to replace them with a nontoy type of fuc such as electricity or gas. Desalu et al. ${ }^{106}$ so termined factors associated with nocturnal, productive anc. ${ }^{1} \mathrm{ry}$ cough among young adults in Nigeria. Th esults indicate that early prevention and treatment $c$ cond ins associated with cough, as well as the modi ation of su alal factors commonly associated with cough, needed in order to reduce respiratory morbidity. Ferren. et al. ${ }^{107}$ surveyed the main congenital lung am tions treated and the principal diagnostic methoc en ployed, as well as the indications for surgical treatmen. nd the results obtained, at a referral facility for pediatric s oracic surgery. Their analysis shows that - lmonary resection for the treatment of congenital lung ma rmations is a safe procedure. presenting low morbidity a d no mortality at a referral facility for pediatric thor ic surgery. Forgiarini et al. ${ }^{108}$ evaluated structural " ations of the lung in rats with diabetes mellitus, by quantifying oxidative stress and DNA damage; they alos ietermined the effects that exogenous superoxide dismutase has on such alterations and conclude that exogenous SOD can reverse changes in the lungs of animals with induced diabetes mellitus. Maranhao et al. ${ }^{109}$ propose a new classification criterion for the differentiation between pleural exudates and transudates quantifying total proteins in pleural fluid (TP-PF) and lactate dehydrogenase in pleural fluid (LDH-PF) exclusively; they also compare this new criterion with the classical criterion in terms of diagnostic yield. They understand that the diagnostic tool was comparable to the classical one and can be used in daily practice. Melo et al. ${ }^{110}$ determined the lung age of patients with morbid obesity and compared it with the chronological age of these patients, emphasizing the premature damage that morbid obesity does to the lungs. Pereira et al. ${ }^{111}$ evaluated the efficacy and safety of two inhalers for Mometasone furoate administration in patients with asthma and find that the use of the single-dose inhaler developed in Brazil is as effective and safe as is that of a standard inhaler in the treatment of patients with asthma. Pinheiro et al. ${ }^{112}$ compared the effects of early vs. late tracheostomy in patients with acute severe brain injury and conclude that early tracheostomy should be considered a first choice for patients with acute severe brain injury. Santana et al. ${ }^{113}$ endeavored to quantify fibrin thrombi in the small and medium-sized pulmonary arteries of patients with Wegener's granulomatosis and report that confocal laser scanning microscopy revealed a significant association between pulmonary microvascular thrombosis and Wegener's granulomatosis. 


\section{REFERENCES}

1. Magedanz EH, Bodanese LC, Guaragna J, Albuquerque LC, Martins V, Minossi SD, et al. Risk score elaboration for mediastinitis after coronary artery bypass grafting. Revista Brasileira De Cirurgia Cardiovascular. 2010;252:154-9.

2. Cadore MP, Guaragna J, Anacker JFA, Albuquerque LC, Bodanese LC, Piccoli JDE, et al. A score proposal to evaluate surgical risk in patients submitted to myocardial revascularization surgery. Revista Brasileira De Cirurgia Cardiovascular. 2010;254:447-56.

3. de Carvalho MRM, Silva N, Klein CH, de Oliveira GMM. Application of the EuroSCORE in coronary artery bypass surgery in public hospitals in Rio de Janeiro, Brazil. Revista Brasileira De Cirurgia Cardiovascular. 2010;252:209-17.

4. Sa M, Soares EF, Santos CA, Figueiredo OJ, Lima ROA, Escobar RR, et al. EuroSCORE and mortality in coronary artery bypass graft surgery at Pernambuco Cardiogologic Emergency Medical Services Pronto Socorro Cardiologico de Pernambuco. Revista Brasileira De Cirurgia Cardiovascular. 2010;254:474-82.

5. Nery RM, Pietrobon RC, Mahmud MI, Zanini ME, Barbisan JN. Comparison of two models of risk stratification in patients submitted to elective coronary artery bypass surgery. Revista Da Associacao Medica Brasileira. 2010;565:547-50.

6. Botega FD, Cipriano G, Lima F, Arena R, da Fonseca JHP, Gerola LR. Cardiovascular behavior during rehabilitation after coronary artery bypass grafting. Revista Brasileira De Cirurgia Cardiovascular. 2010;254:527-33.

7. Martini MR, Barbisan JN. Influence of physical activity during leisure time in patients in the follow-up two years after CABG. Revista Brasileira De Cirurgia Cardiovascular. 2010;253:359-64.

8. Guizilini S, Bolzan DW, Faresin SM, Alves FA, Gomes WJ. Ministernotomy in Myocardial Revascularization Preserves Postoperative Pulmonary Function. Arquivos Brasileiros De Cardiologia. 2010;955:587-92.

9. Barros GF, Santos CD, Granado FB, Costa PT, Limaco RP, Gardenghi G. Respiratory muscle training in patients submitted to coronary arterial bypass graft. Revista Brasileira De Cirurgia Cardiovascular. 2010;254:483-90

10. Hijazi EM. Comparative study of traditional long incision vein harvesting and multiple incisions with small skin bridges in patie ss with coronary artery bypass grafting at King Abdullah Unive, ity Hospital - Jordan. Revista Brasileira De Cirurgia Cardiova ular. 2010;252:197-201.

11. Gabriel EA, Locali RF, Matsuoka PK, Almeida LS, Silva PCV, Is MMD, et al. Pulmonary artery perfusion does not im ove bra natriuretic peptide (BNP) levels in suine experimental res rch. Revista Brasileira De Cirurgia Cardiovascular. 2010;254:516-26

12. Lins RMM, Lima RD, Silva FPV, de Menezes AM, Sal no PR, et al. Treatment of atrial fibrillation using ultrasonic cardiac abla. during valvular heart surgery. Revista Bra De Cirurgia Cardiovascular. 2010;253:326-32.

13. Benfatti RA, Carli AF, da Silva GVR, Edgardo , Dias MAS, oldiano $\mathrm{JA}$, et al. Epsilon-aminocaproic acid influ ce in bleed $\mathrm{ig}$ and hemotransfusion postoperative in mitral va surgery Revista Brasileira De Cirurgia Cardiovascular. 2010;254:510

14. Guedes MAV, Pomerantzeff PMA, Vieira MLC, Grinberg M, Stolf NAG. Mitral valve st ery u wht anterolateral thoracotomy: is the aortic cannulation saf y procedure? Revista Brasileira De Cirurgia Cardiovascular. 2010, 0:322-5.

15. Guedes MAV, Pomerantzeff $\mathrm{P}^{\prime}$ andao MD, Vieira MLC, Leite OA, da Silva MF, et al. Mitral alve re air by D ble Teflon technique: cardiac remodeling analy s by $t$. $1 \mathrm{~m}$. innal echocardiography. Revista Brasileira De Cirur Car' svascular. 2010;254:534-42.

16. Gaia DF, Palma JH, Fer ira C, Souza JAM, Agreli G, Guilhen JCS, et al. Transapical ac ic valve in antation: results of a Brazilian prosthesis. Revista P $\quad$ eira De Cirurg Cardiovascular. 2010;253:293302.

17. do Amaral JJM, Pomeranı \& PMA, Casagrande ISJ, Cestari IA, Gutierrez PS, $C$ olf NG. Analysı of hemodynamic performance of the bovine peric dium valved conduit, implanted in the aortic position in ovines. Rey ta Bras cira De Cirurgia Cardiovascular. 2010;254:543-51.

18. Dias RR, ' $\mathrm{i}$ Of , Fiorel' AI, Pomerantzeff PMA, Dias AR, Mady C, et al. Analysis ortic $r$ is surgery with composite mechanical aortic valve Juit an aly sparing reconstruction. Revista Brasileira De Cir sia C diovascu. 2010;254:491-9.

19. L itola PI paio RO, de Oliveira WA, Boer BN, Tarasoutchi F, - na GS $c$ al. Wa. arin or Aspirin in Embolism Prevention in Patients wit. al Valvulopathy and Atrial Fibrillation. Arquivos Brasileiros De Car 1ogia. 2010:956:749-54.

20. de Campos $y$, de Andrade RR, Silva MAD. Oral anticoagulation in carriers of mechanical heart valve prostheses. Experience of ten years. Revista Brasileira De Cirurgia Cardiovascular. 2010;254:457-65.
21. Maluf MA, Carvalho AC, Carvalho WB. One and a half ventricular repair as an alternative for hypoplastic right ventricle. Revista Brasileira De Cirurgia Cardiovascular. 2010;254:466-73.

22. da Rocha TS, da Silveira AS, Botta AM, Ricachinev y CP, Mulle LD, Nogueira A. Serum lactate as mortality and morbid y mark in infants after Jatene's operation. Revista Brasileira De Cir. ia C? diovasc ar. 2010;253:350-8.

23. de Souza AH, da Fonseca L, Franchi SM, Lianza AC, Bau ra+ jF, da Silva JP. The hypoplastic left heart syndrome is not a risk ctor for Fontan operation. Revista Brasileira B Cirurgia Cardiovascular. 2010;254:506-9.

24. Rosa RFM, Dall'Agnol L, Zen PRG, Pe - VLB, zia o C, Paskulin GA. Oculo-auriculo-vertebral spec am and cardia malformations. Revista Da Associacao Medica Bra leira. 2010;5 :62-6.

25. Coronel CC, Bordignon S, Bueno D, Lima LL, sralla I. Ventilatory function and physical function rioperative variables in heart transplantation. Revista B ileira o Cir gia Cardiovascular. 2010;252:190-6.

26. Yoshimori DY, Cipriano Mair V, nco JNR, Buffolo E. Assessment and medium-term follo up of heart tra plant candidates undergoing low-intensity exercis $\mathrm{k}$ ta Brasileira De Cirurgia Cardiovascular. 2010;253:333-40.

27. Dinkhuysen JJ, Cipullo R, Con ras C, Finger MA, Manrique R, Magalhaes HM Farmacologic test pre implants in hypertension pulmonary el ated a d still in candidates to heterotopic transplantation. Revista rasileir a "urgia Cardiovascular. 2010;253:371-6.

28. de Abreu-S. EO de Quauros AS, Zanettini MT, Gottschall CA Angiographic L ation of Plaque Volume and Cardiovascular Events after Coronary Ster. aplantation. Arquivos Brasileiros De Cardiologia. 2010 - $7 a_{-} 84$

29. Morie G, Ku MG, Matsubara LS, Cerqueira A, Matsubara BB. Quality f $Y$, in Patients with Severe and Stable Coronary Atherosc tic Disease. Arquivos Brasileiros De Cardiologia. 2010;956:69

30. Duarte JJ, Pol s J, Gomes OM, da Silva GVR, Gardenal N, da Silva AF, al. Correlation between right atrial venous blood gasometry and c. iac index in cardiac surgery postoperative. Revista Brasileira De Ciru ia Cardiovascular. 2010;252:160-5.

31. da Si a RG, de Lima GG, Guerra N, Bigolin AV, Petersen LC. Risk inde oroposal to predict atrial fibrillation after cardiac surgery. Revista Bra eira De Cirurgia Cardiovascular. 2010;252:183-9.

32. Atas CEP, de Sa MPL, Bastos ES, Magnanini MMF. Pericardium closure after heart operations: a safety option? Revista Brasileira De Cirurgia Cardiovascular. 2010;25(3):365-70.

Riedi C, Mora CTR, Driessen T, Coutinho MDG, Mayer DM, Moro FL, et al. Relation between respiratory muscle strength with respiratory complication on the heart surgery. Revista Brasileira De Cirurgia Cardiovascular. 2010;254:500-5.

34. Leal JMD, Carnevale FC, Nasser F, Santos ACB, Sousa WD, Zurstrassen $\mathrm{CE}$, et al. Endovascular techniques and procedures, methods for removal of intravascular foreign bodies. Revista Brasileira De Cirurgia Cardiovascular. 2010;252:202-8.

35. Laizo A, Delgado FED, Rocha GM. Complications that increase the time of hospitalization at ICU of patients submitted to cardiac surgery. Revista Brasileira De Cirurgia Cardiovascular. 2010;252:166-71.

36. Sa M, Sa M, Barbosa CH, Silva NPD, de Escobar RR, de Rueda FG, et al. Clinical and surgical profile of patients operated for postinfarction interventricular septal rupture. Revista Brasileira De Cirurgia Cardiovascular. 2010;253:341-9.

37. Ferreira CCD, Peixoto MDG, Barbosa MA, Silveira EA. Prevalence of Cardiovascular Risk Factors in Elderly Individuals treated in the Brazilian Public Health System in Goiania. Arquivos Brasileiros De Cardiologia. 2010;955:621-8.

38. de Arruda ER, Lacerda HR, Moura L, de Albuquerque M, Miranda DD, Diniz GTN, et al. Profile of Patients with Hypertension Included in a Cohort with HIV/AIDS in the State of Pernambuco, Brazil. Arquivos Brasileiros De Cardiologia. 2010;955:640-7.

39. de Queiroz VM, Moreira PVL, de Vasconcelos THC, Vianna RPD Prevalence and Anthropometric Predictors of High Blood Pressure in Schoolchildren from Joao Pessoa - PB, Brazil. Arquivos Brasileiros De Cardiologia. 2010;955:629-34.

40. Monteiro LZ, Fiani CRV, de Freitas MCF, Zanetti ML, Foss MC Decrease in Blood Pressure, Body Mass Index and Glycemia after Aerobic Training in Elderly Women with Type 2 Diabetes. Arquivos Brasileiros De Cardiologia. 2010;955:563-70.

41. Camara LC, Ritti-Dias RM, Forjaz CLD, Greve JM, Santarem JM, Jacob W, et al. Cardiovascular Responses during Isokinetic Muscle Assessment in Claudicant Patients. Arquivos Brasileiros De Cardiologia. 2010;955:571-6.

42. Ribeiro RA, Stella SF, Zimerman LI, Pimentel M, Rohde LE, Polanczyk CA. Cost-Effectiveness of Implantable Cardioverter Defibrillators in Brazil in the Public and Private Sectors. Arquivos Brasileiros De Cardiologia. 2010;955:577-86. 
43. de Aguiar AAF, Mourilhe-Rocha R, Esporcatte R, Amorim LC, Tura BR, de Albuquerque DC. Long-Term Analysis in Acute Coronary Syndrome: are there any Differences in Morbidity and Mortality? Arquivos Brasileiros De Cardiologia. 2010;956:705-12.

44. Aguiar VB, Ochiai ME, Cardoso JN, Del Carlo $\mathrm{CH}$, Morgado PC, Munhoz RT, et al. Relationship between Depression, BNP Levels and Ventricular Impairment in Heart Failure. Arquivos Brasileiros De Cardiologia. 2010;956:732-7.

45. Alves RJ, Campos RN, Nakiri K. Chronic and Regular Use of Statin Prevents Atrial Fibrillation in Period after Cardiac Surgery. Arquivos Brasileiros De Cardiologia. 2010;955:614-9.

46. da Silva CA, Pardi ACR, Goncalves TM, Borin SH. Electrocardiographic Profile and Muscle Glycogen Content of Rats Treated with Nandrolone. Arquivos Brasileiros De Cardiologia. 2010;956:720-4.

47. Diogo LP, Saitovitch D, Biehl M, Bahlis LF, Gutierres MC, O'Keeffe CF, et al. Is There an Association between Non-steroidal Anti-inflammatory Drugs and Contrast Nephropathy? Arquivos Brasileiros De Cardiologia. 2010;956:726-30.

48. Fagundes JE, Castro I. Predictive Value of Resting Heart Rate for Cardiovascular and All-cause Mortality. Arquivos Brasileiros De Cardiologia. 2010;956:713-8.

49. Feliciano-Alfonso JE, Mendivil CO, Ariza IDS, Perez CE. Cardiovascular risk factors and metabolic syndrome in a population of young students from the national university of Colombia. Revista Da Associacao Medica Brasileira. 2010;563:293-8.

50. Kalil RAK, de Salles FB, Giusti, Rodrigues, II CG, Han SW, Sant'Anna $\mathrm{RT}$, et al. VEGF gene therapy for angiogenesis in refractory angina: Phase I/II clinical trial. Revista Brasileira De Cirurgia Cardiovascular. 2010;253:311-21.

51. Gomes OM, Magalhaes MD, Abrantes RD. Myocardium functional recovery protection by omeprazole after ischemia-reperfusion in isolated rat hearts. Revista Brasileira De Cirurgia Cardiovascular. 2010;253:388-92.

52. Minicucci MF, Azevedo PS, Ardisson LP, Okoshi K, Matsubara BB, Matsubara LS, et al. Relevance of the Ventricular Remodeling Pattern in the Model of Myocardial Infarction in Rats. Arquivos Brasileiros De Cardiologia. 2010;955:635-8.

53. de Azambuja LEO, Garrafa V. Jehovah's witnesses attitude towa hemocomponents and hemoderivatives. Revista Da Associacao Mec. Brasileira. 2010;566:705-10

54. Ammirati AL, Watanabe $\mathrm{R}$, Aoqui $C$, Draibe $\mathrm{SA}$, Carvalho AB, Ab sur $\mathrm{H}$ et al. Hemoglobin levels in hemodialysis patients treated with oetin: brazilian experience. Revista Da Associacao Medica rasilei 2010;562:209-13.

55. Macedo PG, Neto EF, da Silva BT, Barreto JR, Maia H/Novà i C, et al. Oral anticoagulation in patients with atrial orillation

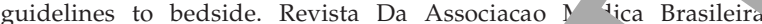
2010;561:56-61.

56. Correia LCL, Barbosa CE, Cerqueira T, Vasconcelos A, Merelic Reis T, et al. Moderate Renal Dysfunction is not Associated with E. ated Troponin $\mathrm{T}$ in Acute Coronary Syndromes srquivos Brasileiros De Cardiologia. 2010;955:600-4.

57. Carvalho AB, Guerra G, Baptista MTM, de ria APM, Mà ii S, Guerra ATM. Cardiovascular and renal anomalies i turner Synd me. Revista Da Associacao Medica Brasileira. 2010;566:65.

58. Roxo JPF, Ponte EV, Ramos DCB, Pimentel L, D_a A, Cruz AA Portuguese-language version of the Control Test: validation for use in Brazil. Jornal Brasileiro De Pr imolo an j;362:159-66.

59. Santos DD, Martins MC, Cipriano SL, I to MC, Cukier A, Stelmach R. Pharmaceutical care for patients with $p_{c}$ istent asthma: assessment of treatment compliance and co valed dications. Jornal Brasileiro De Pneumologia. 2010;36 4-22.

60. Sarinho E, Kunz FC, Be' si N, M a P, o JA, Silva AR. Can multiple doses of BCG vaccine tec against asthma? Jornal Brasileiro De Pneumologia. 2010, 3:281-

61. Sarria EE, Rosa RC 1, Fischer Gb, "rakata VN, da Rocha NS, Mattiello R. Field-test valids of the Braziliar version of the Paediatric Asthma Quality of L Qu onnaire. Jornal Brasileiro De Pneumologia. 2010;364:417-24.

62. Razi E, Mo avi GA. Serum al IgE levels and total eosinophil counts: relations' $\rho$ with treatment response in patients with acute asthma. Jornal asileirs Je Pneumologia. 2010;361:23-8.

63. Reck Fi rman- $\mathrm{F}$ linari D, Barreto SSM, Fiterman J. Poor perception dyspne ollowing methacholine challenge test in patients v. thma. na' rasileiro De Pneumologia. 2010;365:539-44

64. Nelo E, Popon A, Sole D. Exhaled breath temperature, a new biomar asthma control: A pilot study. Jornal Brasileiro De Pneu ologia. $-10 ; 366: 693-9$.

65. PB, Santoro IL, Caetano LB, Cabral ALD, Fernandes ALG. Pen nance of a word labeled visual analog scale in determining the degree $\checkmark$ dyspnea during exercise-induced bronchoconstriction in children and adolescents with asthma. Jornal Brasileiro De Pneumologia. 2010;365:532-8.
66. Dela Bianca ACC, Wandalsen GF, Mallol J, Sole D. Prevalence and severity of wheezing in the first year of life. Jornal Brasileiro De Pneumologia. 2010;364:402-9.

67. de Castro LKK, Neto AC, Ferreira OF. Preva' ace of symptoms of asthma, rhinitis and atopic eczema among st ents $b$ ween 6 and 7 years of age in the city of Londrina, Bra. Jorr Brasil co De Pneumologia. 2010;363:286-92.

68. Brandao HV, Cruz CS, Guimaraes A, Camargos M Cruz AA Predictors of hospital admission due to asthma in aldren and adolescents enrolled in an asthma co program. Jornal Brasileiro De Pneumologia. 2010;366:700-6.

69. Borges MC, Ferraz E, Pontes SMR in A, dei RD, da Silva CS, et al. Development and valid on of an asth knowledge questionnaire for use in Brazil. Jor A Brasileiro Pneumologia. 2010;361: $8-13$.

70. Almeida MLD, Santana PA, ( imaraes A, jurgel RQ, Vianna EO. Asthma and pregnancy: 1 rrcuss for n nates. Jornal Brasileiro De Pneumologia. 2010;363.293-

71. Fonseca MD, Cader A, Danta HM, Bacelar SC, da Silva EB, Leal SMD. Respiratory iscle training grams: impact on the functional autonomy of the ell. Revista Da Associacao Medica Brasileira. 2010:566:642-8.

72. Silva DR, Gazzana MB, KI + MM. Merit of preoperative clinical findings an tional pulmonary evaluation as predictors of postoperative almor rv complications. Revista Da Associacao Medica Brasileir 2010;5

73. Costa D, 'ncal is HA, ae Lima LP, Ike D, Cancelliero KM, Montebelo MID. New ence values for maximal respiratory pressures in the Brazilian popu. on. Jornal Brasileiro De Pneumologia. 2010;363:306-

74. D quin nodrigues SC, Barros JA, Rubin AS, Rosario NA, Pereira CA. Pre cting reduced TLC in patients with low FVC and a normal or el ed FEV(1)/FVC ratio. Jornal Brasileiro De Pneumologia. 2010;36 $\quad 160-7$.

75. Logrado S, Sena EM, Matos RJD, da Silva TML, de Oliveira TR, Mendes $\mathrm{KMB}$, et al. Impact that positive reinforcement during pirometry has on the measurement of VC in healthy volunteers. nal Brasileiro De Pneumologia. 2010;362:205-9.

76. R lrigues MT, Fiterman-Molinari D, Barreto SSM, Fiterman J. The role the $\mathrm{FEF}(50 \%) / 0.5 \mathrm{FVC}$ ratio in the diagnosis of obstructive lung iseases. Jornal Brasileiro De Pneumologia. 2010;361:44-50.

Silveira JM, Gastaldi AC, Boaventura CD, Souza HC. Inspiratory muscle training in quadriplegic patients. Jornal Brasileiro De Pneumologia. 2010;363:313-9.

78. Felix EA, Andrade CF, Cardoso PFG, Thiesen GC, Antonio ACP Martins LK, et al. Ventilation strategy and its influence on the functional performance of lung grafts in an experimental model of single lung transplantation using non-heart-beating donors. Jornal Brasileiro De Pneumologia. 2010;365:554-61.

79. Goncalves BD, Cavalini LT, Valente JG. Epidemiological monitoring of tuberculosis in a general teaching hospital. Jornal Brasileiro De Pneumologia. 2010;363:347-55.

80. Gupta S, Shenoy VP, Bairy I, Muralidharan S. Comparison among three cold staining methods in the primary diagnosis of tuberculosis: a pilot study. Jornal Brasileiro De Pneumologia. 2010;365:612-6.

81. Lundgren FLC, Costa AM, Figueiredo LC, Borba PC. Hemoptysis in a referral hospital for pulmonology. Jornal Brasileiro De Pneumologia. 2010;363:320-4.

82. Maciel ELN, Guidoni LM, Favero JL, Hadad DJ, Molino LP, Jonhson JL, et al. Adverse effects of the new tuberculosis treatment regimen recommended by the Brazilian Ministry of Health. Jornal Brasileiro De Pneumologia. 2010;362:232-8.

83. Marques M, Cunha EAT, Ruffino-Netto A, Andrade SMD. Drug resistance profile of Mycobacterium tuberculosis in the state of Mato Grosso do Sul, Brazil, 2000-2006. Jornal Brasileiro De Pneumologia. 2010;362:224-31

84. Pedrozo C, Sant'Anna CC, March M, Lucena SC. Efficacy of the scoring system, recommended by the Brazilian National Ministry of Health, for the diagnosis of pulmonary tuberculosis in children and adolescents, regardless of their HIV status. Jornal Brasileiro De Pneumologia. 2010;361:92-8

85. Martinelli LMB, Boas P, Queluz TT, Yoo HHB. Morphological prognostic factors in nosocomial pneumonia: an autopsy study. Jornal Brasileiro De Pneumologia. 2010;361:51-8.

86. Mattiello R, Mallol J, Fischer GB, Mocelin HT, Rueda B, Sarria EE. Pulmonary function in children and adolescents with postinfectious bronchiolitis obliterans. Jornal Brasileiro De Pneumologia. 2010;364:4539.

87. Senturk E, Telli M, Sen S, Cokpinar S. Thoracic catheter-related infections. Jornal Brasileiro De Pneumologia. 2010;366:753-8.

88. Melo CBD, Sarmento PA, Imaeda CJ, Daud DF, Hasimoto FN, Leao LEV. Descending necrotizing mediastinitis: minimally invasive thoracic surgical treatment. Jornal Brasileiro De Pneumologia. 2010;366:812-8. 


\section{Patel KK et al.}

89. Fernandes FLA, Pavezi VAL, Dias SA, Pinto RMC, Stelmach R, Cukier A. Short-term effect of tiotropium in COPD patients being treated with a beta(2) agonist. Jornal Brasileiro De Pneumologia. 2010;362:181-9.

90. Ferrari R, Tanni SE, Lucheta PA, Faganello MM, do Amaral RAF, Godoy I. Gender differences in predictors of health status in patients with COPD. Jornal Brasileiro De Pneumologia. 2010;361:37-43.

91. Araujo ZTD, Holanda G. Does the BODE index correlate with quality of life in patients with COPD? Jornal Brasileiro De Pneumologia. 2010;364:447-52.

92. Camargo L, Pereira CAD. Dyspnea in COPD: Beyond the modified Medical Research Council scale. Jornal Brasileiro De Pneumologia. 2010;365:571-8.

93. Chatkin G, Chatkin JM, Aued G, Petersen GO, Jeremias ET, Thiesen FV. Evaluation of the exhaled carbon monoxide levels in smokers with COPD. Jornal Brasileiro De Pneumologia. 2010;363:332-8.

94. Machado L, Saad IAB, Honma HN, Morcillo AM, Zambon L. Evolution of performance status, body mass index, and six-minute walk distance in advanced lung cancer patients undergoing chemotherapy. Jornal Brasileiro De Pneumologia. 2010;365:588-94.

95. Franceschini J, Jardim JR, Fernandes ALG, Jamnik S, Santoro IL. Reproducibility of the Brazilian Portuguese version of the European Organization for Research and Treatment of Cancer Core Quality of Life Questionnaire used in conjunction with its lung cancer-specific module. Jornal Brasileiro De Pneumologia. 2010;365:595-602.

96. Rodrigues GD, Severo CB, Oliveira FD, Moreira JD, Prolla JC, Severo LC. Association between paracoccidioidomycosis and cancer. Jornal Brasileiro De Pneumologia. 2010;363:356-62

97. Marchi E, Vargas FS, Madaloso BA, Carvalho MV, Terra RM, Teixeira LR. Pleurodesis for malignant pleural effusions: A survey of physicians in South and Central America. Jornal Brasileiro De Pneumologia. 2010;366:759-67.

98. Brandao DS, Haddad R, Marsico GA, Boasquevisque CHR. Clinicopathological aspects of and survival in patients with clinical stage 1 bronchioloalveolar carcinoma. Jornal Brasileiro De Pneumologia. 2010;362:167-74.

99. Coelho AC, Knorst VM, Gazzana MB, Barreto SSV. Predictors of physical and mental health-related quality of life in patients with interstitial lung disease: a multifactorial analysis. Jornal Brasileiro De Pneumologia. 2010;365:562-70.

100. Antunes VB, Meirelles GDP, Jasinowodolinski D, Pereira CAD, Verrastro CGY, Torlai FG, et al. Observer agreement in the diagno is of interstitial lung diseases based on HRCT scans. Jornal Brasileir Je Pneumologia. 2010;361:29-36.

101. Navarro FB, da Costa FDA, Mulinari LA, Pimentel GK, Roder JC Vieira ED, et al. Evaluation of the biological behavior of decellu 'zer' pulmonary homografts: an experimental sheep model. Revista Brasileira De Cirurgia Cardiovascular. 2010;253:377-87.

102. Pego-Fernandes PM, Mariani AW, de Medeiros IT Pereira AED, Fernandes FG, Unterpertinger FD, et al. Ex vivo lus evaluation and reconditioning. Revista Brasileira De Cirurg Card vascular. 2010;254:441-6.

103. Athanazio RA, Rached SZ, Rohde C, Pinto RC, randes LA Stelmach R. Should the bronchiectasis treatment given to stic orosis patients be extrapolated to those with bronchiectasis from ot. causes? Jornal Brasileiro De Pneumologia. 2010;36 125-31.

104. de Souza RM, de Andrade FM, Moura ABD, ixeira PJZ kespiratory symptoms in charcoal production workers in citi of Lindolfo Collor, Ivoti and Presidente Luc a, vrazil. Jon Brasileiro De Pneumologia. 2010;362:210-7.

105. Desalu OO, Adekoya AO, Ampit BA. Increas risk of respiratory symptoms and chronic bronchitis women us ig biomass fuels in Nigeria. Jornal Brasileiro De neumc via. 2010 o4:441-6.

106. Desalu OO, Salami AK, Seid. A, On AB, Fadeyi A. Factors associated with nocturnal roduct. and dry cough in the young adult population of Nigeria. I nal Brasileir e Pneumologia. 2010;363:325pop

107. Ferreira HPD, Fisch GB, licetti JC, Camargo JDP, Andrade CF. Surgical treatment of conger l lung malformations in pediatric patients. Jornal Br-ileiro De Pneu. ologia. 2010;362:175-80.

108. Forgiarini LA, etzı nn NA, Tieppo J, Picada JN, Dias AS, Marroni NAP. Lung eration rat model of diabetes mellitus: effects of antioxidant erapy. rnal s ileiro De Pneumologia. 2010;365:579-87.

109. Maranhao BL, ${ }^{1} \mathrm{~V}$ ? $\mathrm{CT}$, Chibante AMD, Cardoso GP. Determination of total proteins an ctate dehydrogenase for the diagnosis of pleural transudates and exu s: redefining the classical criterion with a new statis a. nach. Jornal Brasileiro De Pneumologia. 2010;364:468-74.

110. Melo S 'D, de M. de Melo EV, de Menezes RS, de Castro VL, Barreto SP Accelerated lung aging in patients with morbid obesity. Jornal Bra iro De Pneumologia. 2010;366:746-52.

111. Pereira CA Vianna FF, Cukier A, Stelmach R, de Oliveira JCA, Carvalho EV, $\rightarrow$ al. Efficacy and safety of two dry-powder inhalers for ho administration of mometasone furoate in asthma patients. Jornal Br. 'eiro De Pneumologia. 2010;364:410-6.

112. Pinh o BD, Tostes RD, Brum CI, Carvalho EV, Pinto SPS, de Oliveira JCA. Irly versus late tracheostomy in patients with acute severe brain injur Jornal Brasileiro De Pneumologia. 2010;361:84-91.

11. Sar ana ANC, Ab'Saber AM, Teodoro WR, Capelozzi VL, Barbas CSV. 1. iombosis in small and medium-sized pulmonary arteries in Wegener's granulomatosis: A confocal laser scanning microscopy study. Jornal Brasileiro De Pneumologia. 2010;366:724-30. 